\title{
Corrigendum: Changes in Blood
} Factors and Ultrasound Findings in Mild Cognitive Impairment and Dementia

\author{
Kyoungjoo Cho, Jihye Kim and Gyung W. Kim* \\ Department of Neurology, College of Medicine, Yonsei University, Seoul, South Korea
}

Keywords: dementia, vascular disease, mild cognitive impairment, blood factor analysis, atherosclerosis

\section{OPEN ACCESS}

Edited and reviewed by:

Mohammad Amjad Kamal, King Fahad Medical Research Center, King Abdulaziz University, Saudi Arabia

${ }^{*}$ Correspondence: Gyung W. Kim gyungkim@yuhs.ac

Received: 17 January 2018 Accepted: 30 January 2018 Published: 13 February 2018

Citation:

Cho K, Kim J and Kim GW (2018) Corrigendum: Changes in Blood Factors and Ultrasound Findings in Mild Cognitive Impairment and Dementia.

Front. Aging Neurosci. 10:33. doi: 10.3389/fnagi.2018.00033

\section{A corrigendum on}

Changes in Blood Factors and Ultrasound Findings in Mild Cognitive Impairment and Dementia

by Cho, K., Kim, J., and Kim, G. W. (2017). Front. Aging Neurosci. 9:427. doi: 10.3389/fnagi.2017. 00427

In the published article, the first affiliation was incorrect. Instead of "(Department of Life Science, Kyonggi University, Suwon, South Korea)", it should be "(Department of Neurology, College of Medicine, Yonsei University, Seoul, South Korea)". The authors apologize for this error and state that this does not change the scientific conclusions of the article in any way.

The incorrect affiliation has been removed and the article has been updated.

Conflict of Interest Statement: The authors declare that the research was conducted in the absence of any commercial or financial relationships that could be construed as a potential conflict of interest.

Copyright $\odot 2018$ Cho, Kim and Kim. This is an open-access article distributed under the terms of the Creative Commons Attribution License (CC BY). The use, distribution or reproduction in other forums is permitted, provided the original author(s) and the copyright owner are credited and that the original publication in this journal is cited, in accordance with accepted academic practice. No use, distribution or reproduction is permitted which does not comply with these terms. 